\title{
Global methaemoglobinaemia research output (1940-2013): a bibliometric analysis
}

\author{
Sa'ed H. Zyoud ${ }^{1,2,3}$, Samah W. Al-Jabi ${ }^{2}$, Waleed M. Sweileh ${ }^{4}$, Suleiman Al-Khalii ${ }^{5}$, Malik Alqub ${ }^{5}$ \\ and Rahmat Awang ${ }^{3}$
}

\begin{abstract}
Bibliometric studies, which involve the use of statistical methods, are increasingly being used for research assessment. A bibliometric analysis was conducted to evaluate the publication pattern of methaemoglobinaemia research output at the global level based on the Scopus database. We analysed selected documents with "methemoglobinemia", or "methaemoglobinaemia" as a part of the title and reported the following parameters: trends of publication output, country of publication, journal pattern, collaborative measures, citations pattern, and institute productivity. A total of 1770 articles were published worldwide. The time trend for the number of articles showed an increase after 2000. The highest number of articles related to methaemoglobinaemia was from the USA ( $24.8 \%)$, followed distantly by the UK (4.5\%), India (3.7\%), and France (3.7\%). No data related to methaemoglobinaemia were published from 152 countries. The total number of citations at the date of data collection was 10,080, with an average of 5.7 citations per document. The USA and UK had the highest $h$-index of 31 and 14 , respectively, and six countries had an $h$-index of 9-14. It is notable that Canada was ranked eighth in the number of publications but fourth in $h$-index and India was ranked third in the number of publications but eighth in $h$-index. Furthermore, Canada produced the most internationally collaborated papers out of the total number of publications for each country (16.1\%), followed by the UK (13.9\%). This bibliometric analysis provides data contributing to a better understanding of the methaemoglobinaemia research field. The number of publications on methaemoglobinaemia increased significantly after 2000. The USA was the most productive country as measured by total publications. The USA and UK achieved the highest $h$-index in the field of methaemoglobinaemia research, signifying a higher quality of research than other countries.
\end{abstract}

Keywords: Bibliometric, Citations, $h$-index, Methaemoglobinaemia, Scopus database

\section{Background}

Methaemoglobinaemia is a disorder that occurs when haemoglobin in the blood is oxidized to form methaemoglobin (MetHb), rendering it unable to transport oxygen. Furthermore, when the MetHb concentration is elevated in red blood cells, it leads to tissue hypoxia (Skold et al. 2011; Cortazzo and Lichtman 2014). Patients are particularly susceptible to worsening methaemoglobinaemia in the presence of oxidizing agents (Mitsides et al. 2014; Sohn et al. 2014; Wieringa et al. 2014). Medications or agents such as anaesthetics

\footnotetext{
*Correspondence: samahjabi@yahoo.com

2 Department of Clinical and Community Pharmacy, College of Medicine and Health Sciences, An-Najah National University, Nablus 44839, Palestine

Full list of author information is available at the end of the article
}

(e.g. lidocaine), antibiotics (e.g. sulphanilamide and dapsone), nitrites (e.g. nitroglycerin/nitric oxide), hair dyes, and curing salt are the most likely causative agents for Methaemoglobinaemia (Cortazzo and Lichtman 2014; Mitsides et al. 2014; Wieringa et al. 2014).

There is an individual variation to oxidize $\mathrm{Hb}$, and this may lead to variations in responses to ingestion of the previously mentioned agents (Cortazzo and Lichtman 2014). Healthy people can tolerate low levels of MetHb without difficulty (Skold et al. 2011). Cyanosis and hypoxia are observed often due to reduction in peripheral oxygen saturation measurements (Skold et al. 2011), so an increase in MetHb can lead to dyspnoea, headache, dizziness, seizures, acidosis, arrhythmias, coma, and death (Skold et al. 2011; Cortazzo and Lichtman 2014). Early recognition of methaemoglobinaemia is important

\section{望 Springer}


because removal or stopping of the causative agent is the first line in treatment (Skold et al. 2011).

Bibliometric studies, which involve the use of statistical methods, are increasingly being used for research assessment (Wallin 2005; Zyoud et al. 2014b, c, d). Methods used in bibliometric studies are mainly quantitative, but can be used to assess the quality of research productivity for a particular country or institution (Wallin 2005; Abramo et al. 2009; Smith 2012). Several recent studies have analysed the scientific research productivity related to various diseases (Sweileh et al. 2014a, b, 2015a, b, c). In point of fact, the assessment of scientific research productivity in the field of haematology has been poorly investigated to date, and only a small number of international bibliometric studies have been published within the field of haematology (Morimoto et al. 2003; Acevedo et al. 2014). To the best of our knowledge, no study until now has been concerned with the assessment of research productivity in the field of methaemoglobinaemia originating worldwide. The objective of the presented study was to analyse the publication pattern of methaemoglobinaemia research output at the global level to provide an accurate overview of scientific output over time and to develop future strategies for research in this area.

\section{Methods}

\section{Search strategy}

The search strategy used in this study was similar to most recent bibliometric studies from our research group (Zyoud et al. 2014a, b, c, d, 2015a, c). Data were obtained from the online version of the SciVerse Scopus. This scientific database embraces the core academic journals related to the subject of interest (Smith 2009, 2010), and it also has a high number of journals in comparison to PubMed and Web of Science (Falagas et al. 2008).

The search conducted in Scopus covered papers published during all the previous years and up to 31 December 2013 whose title included the following keywords: "methemoglobinemia", and "methaemoglobinaemia". The resulting search was as follows: TITLE ("methemoglobinemia") OR TITLE ("methaemoglobinaemia"). We excluded documents that were published as an erratum.

The collected data were analysed to create the following information: year of publication, subject categories, publication counts of the journals, citations received by the publications, collaboration among different countries, assessing research in terms of the most prolific institutions, and impact factors of the publishing journals. Bibliometric indicators were presented in rank order using the standard competition ranking (Zyoud et al. 2014a, b, c, d, 2015a, c). Only the ten top-ranked were considered and interpreted. The quality of research productivity was measured using the $h$-index, impact factor (IF), and the
SCImago Journal Rank (SJR) indicator. Impact factors were taken from the Journal Citation Report (JCR) published in 2012. SJR was taken fromthe SCImago website (Scimago 2014). The $h$-index was introduced by Hirsch (Hirsch 2005) as an alternative to the impact factor to characterize the significance of a scientist's research publications. The $h$-index is the largest number $h$ such that $h$ papers have at least $h$ citations (Hirsch 2005). For example, an $h$-index of eight means that the author has eight papers with at least eight citations each.

\section{Statistical analysis}

All statistical analyses were performed using SPSS software (version15.0; SPSS, Chicago, IL).We used Pearson's correlation analysis to determine significant changes in publication number over time. All data are expressed as medians and interquartile ranges (IQRs) or numbers with percentages.

\section{Results}

As a result, 1770 publications were obtained. Of all the publications retrieved from the database, original articles accounted for $76.3 \%$, followed by letters to the editor $(10.1 \%)$, review articles (4.0\%), and others (e.g. editorial material, meeting abstract and book review; $9.7 \%$ ). Publications in the field of methaemoglobinaemia were seen as early as 1940 s followed by a gradual increase that reached the maximum after 2000 (Table 1). Pearson's correlation test showed a significant, strong positive correlation between time and number of publications $(\mathrm{r}=0.88$, $P<0.001$ ) between 1940 and 2013. Around $33.2 \%$ of all retrieved publications were published during 2000-2013, with a steady publication rate of around 42 documents per year overall (Table 1). The first article related to methaemoglobinaemia in Scopus was published by Carey and Wilson in The Journal of Pediatrics in 1940(Carey and Wilson 1940). The language in which the publications were written was predominantly English $(n=1264$,

Table 1 Total number of articles included in a bibliometric analysis of worldwide publications related to methaemoglobinaemia from 1940 to 2013

\begin{tabular}{lc}
\hline Year of publication & Total $\mathbf{n}=\mathbf{1 7 7 0}(\mathbf{\%})$ \\
\hline $1940-1949$ & $29(1.8)$ \\
$1950-1959$ & $98(5.4)$ \\
$1960-1969$ & $218(12.3)$ \\
$1970-1979$ & $246(13.9)$ \\
$1980-1989$ & $276(15.6)$ \\
$1990-1999$ & $315(17.8)$ \\
$2000-2009$ & $389(22.0)$ \\
$2010-2013$ & $199(11.2)$ \\
\hline
\end{tabular}


$71.4 \%)$, followed by French ( $\mathrm{n}=106,6 \%)$, German $(\mathrm{n}=83,4.7 \%)$, and Spanish $(\mathrm{n}=56,3.2 \%)$.

The retrieved documents were published in 60 countries. In Table 2 we see the ten most productive countries in the field "methaemoglobinaemia". The highest number of articles related to methaemoglobinaemia was from the USA ( $24.8 \%)$, followed distantly by the UK (4.5\%), India (3.7 \%), and France (3.7 \%) (Table 2). Among 212 different countries or territories registered in the World Bank online database (World Bank Group 2013), 152 (71.7 \%) countries had not published any independent publications related to methaemoglobinaemia.

The total number of citations at the date of data collection (30 January 2014) was 10,080, with an average of 5.7 citations per document and a median (interquartile range) of $1(0.0-6)$. The $h$-index for all publications was 40 (i.e., 40 documents had been cited at least 40 times at the date of data collection). The USA and UK had the highest $h$-index of 31 and 14, respectively, and six countries had an $h$-index of 9-14. It is notable that Canada was ranked eighth in the number of publications but fourth in $h$-index, and India was ranked third in the number of publications but eighth in $h$-index. Furthermore, Canada produced the most multinational collaborated papers out of the total number of publications for each country (16.1 \%) followed by the UK (13.9\%); (Table 2).

Articles were published in 859 journals. Table 3 lists the ten most productive journals with both IF and SJR. Twenty-eight documents (1.48\%) were published in the Journal of Pediatrics, whereas 24 (1.36 \%) were published in the New England Journal of Medicine, 20 (1.13\%) were published in Blood, and 20 (1.13\%) were published in Anesthesiology.

The ten most cited papers of the found bibliography are presented in Table 4 (Curry 1982; Barker et al. 1989; Nilsson et al. 1990; Mansouri and Lurie 1993; Coleman and Coleman 1996; Fan and Steinberg 1996; Wright et al. 1999; Ash-Bernal et al. 2004; Fewtrell 2004; Guay 2009). According to this list, emergency medicine, environmental and toxicological aspects, and drug safety have mainly captured the attention of the researchers throughout the period of publication. The top ten institutions were ranked by the number of articles (Table 5). Among the top ten institutions, six were in the USA. All the top institutions appeared in the top ten ranking countries, except Brazil and China.

\section{Discussion}

In the current study, bibliometric indicators were used to evaluate the methaemoglobinaemia research output at the global level. The main strengths of this study are that it is the first bibliometric study on methaemoglobinaemia and it reveals the quantity and quality of methaemoglobinaemiabased research at the global level. In our study, publications related to methaemoglobinaemia first appeared in the $1940 \mathrm{~s}$ and rapidly increased after 2000, with one-third of the articles (33.2\%) being published between 2000 and 2013. Scientific publications related to methaemoglobinaemia were similar to the general evolution in scientific research output observed over the last decade and especially in

Table 2 The top ten most productive countries with regard to publishing articles related to methaemoglobinaemia

\begin{tabular}{llllllll}
\hline SCR $^{\mathbf{a}}$ & Countries & $\begin{array}{l}\text { Total number } \\
\text { of articles for the } \\
\text { whole period (\%) }\end{array}$ & h-index & $\begin{array}{l}\text { Median (Q1-Q3) } \\
\text { of citation }\end{array}$ & $\begin{array}{l}\text { Average } \\
\text { citation }\end{array}$ & $\begin{array}{l}\text { Collaboration } \\
\text { with other } \\
\text { countries }\end{array}$ & $\begin{array}{l}\text { Number (\%) } \\
\text { uments with interna- } \\
\text { tional collaboration }\end{array}$ \\
\hline 1st & USA & $438(24.8)$ & 31 & $6(2-12)$ & 11.2 & 18 & $26(5.9)$ \\
2nd & UK & $79(4.5)$ & 14 & $5(1-11)$ & 11.5 & 9 & $11(13.9)$ \\
3rd & India & $66(3.7)$ & 7 & $1(0.0-4)$ & 3.3 & 7 & $7(10.6)$ \\
3rd & France & $66(3.7)$ & 9 & $1(0.0-3.5)$ & 3.8 & 2 & $2(3.0)$ \\
5th & Japan & $62(3.5)$ & 11 & $1(0.0-8)$ & 5.8 & 5 & $6(9.7)$ \\
6th & Germany & $53(3.0)$ & 10 & $1(0.0-8.5)$ & 4.6 & 3 & $5(9.4)$ \\
7th & Turkey & $47(2.7)$ & 6 & $1(0.0-3.0)$ & 2.2 & 2 & $4(8.5)$ \\
8th & Canada & $31(1.8)$ & 10 & $7(2-15)$ & 10.4 & 4 & $5(16.1)$ \\
9th & Israel & $24(1.4)$ & 9 & $5(0.3-10.8)$ & 11.3 & 1 & $1(4.2)$ \\
10th & Australia & $21(1.2)$ & 5 & $3(0.0-5)$ & 5.1 & 4 & $2(9.5)$ \\
10th & Spain & $21(1.2)$ & 5 & $1(0.0-4)$ & 4.6 & 2 & $2(9.5)$
\end{tabular}

SCR standard competition ranking, Q1-Q3 lower quartile-upper quartile

a Equal countries have the same ranking number, and then a gap is left in the ranking numbers

b The term "collaboration with other countries" refers to the number of other countries represented among authors were collaborated with authors from a particular country

c Percentage of documents with international authors out of the total number of documents for each country

d The term "international collaboration" refers to the number of published articles from a particular country and were co-authored by researchers from multiple countries 
Table 3 Ranking of the top ten journals in which articles related to methaemoglobinaemia were published with their corresponding impact factors

\begin{tabular}{|c|c|c|c|c|c|}
\hline $\mathrm{SCR}^{\mathrm{a}}$ & Journal & Frequency (\%) & SJR & IF $(2012)^{b}$ & Subject categories $^{c}$ \\
\hline $1 \mathrm{st}$ & Journal of Pediatrics & $28(1.58)$ & 1.2 & 4.035 & Paediatrics \\
\hline 2nd & New England Journal of Medicine & $24(1.36)$ & 10.16 & 51.658 & Medicine, general and internal \\
\hline $3 r d$ & Blood & $20(1.13)$ & 4.55 & 9.060 & Haematology \\
\hline $3 r d$ & Anesthesiology & $20(1.13)$ & 2.05 & 5.163 & Anaesthesiology \\
\hline 5 th & Pediatrics & $15(0.85)$ & 2.54 & 5.119 & Paediatrics \\
\hline 6 th & Journal of Emergency Medicine & $14(0.79)$ & 0.47 & 1.331 & Emergency Medicine \\
\hline 7th & Annals of Emergency Medicine & $13(0.73)$ & 1.4 & 4.285 & Emergency medicine \\
\hline 7th & Orvosi Hetilap & $13(0.73)$ & 0.16 & NA & Medicine $^{d}$ \\
\hline 9th & Annals of Pharmacotherapy & $12(0.68)$ & 0.82 & 2.567 & Pharmacology and pharmacy \\
\hline 9th & Journal of the American Medical Association & $12(0.68)$ & 4.84 & 29.978 & Medicine, general and internal \\
\hline 9th & British Medical Journal & $12(0.68)$ & 2.327 & 17.215 & Medicine, general and internal \\
\hline 9th & Toxicology and Applied Pharmacology & $12(0.68)$ & 1.33 & 3.975 & Pharmacology and pharmacy; toxicology \\
\hline
\end{tabular}

SCR standard competition ranking, SJR SCImago Journal Rank, NA not available, IF impact factor

a Equal journals have the same ranking number, and then a gap is left in the ranking numbers

b The impact factor was reported according to the Institute for Scientific Information (ISI) journal citation reports (JCR) 2012

c Subject categories were reported according to the ISI JCR 2012

d Subject categories were reported according to the SCImago Web site

Table 4 Top ten cited documents related to methaemoglobinaemia in scopus

\begin{tabular}{llll}
\hline SCR & Authors and year of publication & Source title & Cited by \\
\hline 1st & Wright et al. (1999) & Annals of Emergency Medicine & 250 \\
2nd & Coleman and Coleman (1996) & Drug Safety & 148 \\
3rd & Mansouri and Lurie (1993) & American Journal of Hematology & 147 \\
4 th & Fan and Steinberg (1996) & Regulatory Toxicology and Pharmacology & 138 \\
5 th & Barker et al. (1989) & Anesthesiology & 137 \\
6 th & Ash-Bernal et al. (2004) & Medicine & 108 \\
7th & Curry (1982) & Annals of Emergency Medicine & 95 \\
8 th & Guay (2009) & Anesthesia and Analgesia & 84 \\
9th & Fewtrell (2004) & Environmental Health Perspectives & 83 \\
10th & Nilsson et al. (1990) & British Journal of Anaesthesia & 79 \\
\hline
\end{tabular}

SCR standard competition ranking

the last few years (Cheng and Zhang 2013; Delirrad et al. 2013; Lopez-Munoz et al. 2013; Sweileh et al. 2013; Zyoud et al. 2014a). Another aspect of interest for the current study in relation to the scientific publications related to methaemoglobinaemia is research paper quality. It should be noted that three of the top ten journals in which articles related to methaemoglobinaemia were published carry IFs greater than ten and have significant impacts in the field of medicine: New England Journal of Medicine, Journal of the American Medical Association, and British Medical Journal.

As shown in our study, the principal finding of this study is that in absolute terms of numbers of articles published in the field of methaemoglobinaemia, the USA is by far the largest contributor. This finding agrees with similar bibliometric studies (Zyoud et al. 2014b; Rymer and Choa 2015; Zyoud et al. 2015a, c). In countries such as the USA, UK, India, France, and Japan, the total output of scientific publications related to methaemoglobinaemia accounted for more than $40 \%$ of global research output. This activity in the field of methaemoglobinaemia may be related to population size or socio-economic factors associated with these countries (Miro et al. 2009; Zyoud et al. 2015a). Furthermore, the number of active researchers, size of funding, prevalence of the disease in certain population, and research competition probably played a role in increasing the number of publications from these countries (Rahman and Fukui 2001, 2003; Man et al. 2004; 
Table 5 Top ten most highly productive institutions that published articles related to methaemoglobinaemia

\begin{tabular}{llc}
\hline SCR $^{\mathbf{a}}$ & Institution, country & No. of documents (\%) \\
\hline 1st & VA Medical Center, USA & $16(0.90)$ \\
2nd & The Institut National de la Santé et de la Recherche Médicale (INSERM), France & $8(0.45)$ \\
2nd & Universidade de Sao Paulo, Brazil & $8(0.45)$ \\
2nd & Belfast Health and Social Care Trust, UK & $8(0.45)$ \\
5 th & Mayo Clinic, USA & $7(0.40)$ \\
5 th & All India Institute of Medical Sciences, India & $7(0.40)$ \\
5 th & Kyushu University, Japan & $7(0.40)$ \\
5 th & University of Liverpool, UK & $7(0.40)$ \\
9 th & Kanazawa University, Japan & $7(0.40)$ \\
9 th & Duke University School of Medicine, USA & $6(0.34)$ \\
9 th & Geisel School of Medicine at Dartmouth, USA & $6(0.34)$ \\
9 th & University of Florida, USA & $6(0.34)$ \\
9 th & Hopital Edouard Herriot, France & $6(0.34)$ \\
9 th & Cleveland Clinic Foundation, USA & $6(0.34)$ \\
9 th & Queen's University Belfast, UK & $6(0.34)$ \\
9 th & Fuzhou General Hospital PLA Nanjing District, China & $6(0.34)$ \\
\hline
\end{tabular}

SCR standard competition ranking

a Equal institutions have the same ranking number, and then a gap is left in the ranking numbers

Benamer and Bakoush 2009). The current study indicate that Israel and Turkey have produced the most research articles from the Middle East region, whereas India, Japan, and Australia are the major research contributors from the Asia-Pacific region, while the UK and France have produced the most research articles from Europe. The top ten most productive countries of this study comprise many countries that are familiar to other scientific productivity rankings (Essential Science Indicators 2012). We are unable to interpret these findings in light of other results, as we have not found any comparative studies. However, previous bibliometric studies have reported similar findings (Li et al. 2013; Ramos et al. 2013; Sweileh et al. 2014b).

The current study shows that the $h$-index of countries with a high number of internationally collaborated articles, such as the USA and the UK, is markedly higher than that of countries with a low number of internationally collaborated articles. Several studies showed that more international collaboration may lead to more influential publications due to shared research ideas and increased citations and visibility (Foley and Della Sala 2014; Freeman and Huang 2014; Li and Zhao 2015). The USA and UK achieved the highest $h$-index in the field of methaemoglobinaemia research, signifying a higher quality of research than other countries. The scientific research has shown an enormous interest in the $h$-index, as shown by the high number of publications on this subject (Wykes et al. 2013; Therattil et al. 2014; Zhang et al. 2015). The $h$-index allows differentiation of the scientific productivity of a researcher with objectivity and accordingly may play an important role when making decisions about awarding prizes, fund allocation, and promotion (Costas and Bordons 2007).

The articles that were published before 2000 were the most frequently cited. Articles that are highly cited are generally most read and referenced and likely to be influential publications within a particular field (Lipsman et al. 2014; Sharma and Lawrence 2014). Furthermore, that a publication is highly cited serves as an indication for its influence within a discipline (Cardona and Sanz 2014; Hsu and Ho 2014; Sharma and Lawrence 2014). The average number of citations per document obtained in our study is similar to that reported in toxicological journals but slightly less than that reported in other scientific journals (Bird 2008; Jang and Rusyniak 2011). Citations for publications in toxicology disciplines are usually low compared with those in other scientific disciplines (Zyoud et al. 2014a, c, 2015b, d).

This study has few limitations. Most were similar to recent bibliometric studies from our research group (Zyoud et al. 2014a, b, c, d, 2015a, c). First of all, some articles could not be found, mainly because the search was limited to keywords "methemoglobinemia" and "methaemoglobinaemia" in the title. Therefore, false negative results are a possibility. Additionally; the limitation of this study was in using the Scopus database alone; therefore it is possible that articles published in non-Scopus-cited journals may be missing from the analysis. 


\section{Conclusions}

This bibliometric analysis provides data contributing to a better understanding of the methaemoglobinaemia research field. The number of publications on methaemoglobinaemia increased significantly after 2000 . The USA was the most productive country as measured by total publications. The USA and UK achieved the highest $h$-index in the field of methaemoglobinaemia research, signifying a higher quality of research than other countries. The present data reveal promising progress for research activity in the field of methaemoglobinaemia. Research activity and number of publications may be greatly enhanced by committing more to international collaborative research projects related to methaemoglobinaemia.

\section{Abbreviations}

IFs: impact factors; JCR: Journal Citation Report; MetHb: methaemoglobin; SJR: SCImago Journal Rank.

\section{Authors' contributions}

All authors were involved in drafting the article, and all authors approved the final version to be submitted for publication. SZ, SA, and WS conceptualized, designed the study, performed the statistical analyses, and drafted the manuscript. SuA, MA, and RA helped to conceptualize and design the study, and assisted in final write-up of the manuscript. All authors read and approved the final manuscript.

\section{Author details}

${ }^{1}$ Poison Control and Drug Information Center (PCDIC), College of Medicine and Health Sciences, An-Najah National University, Nablus 44839, Palestine. 2 Department of Clinical and Community Pharmacy, College of Medicine and Health Sciences, An-Najah National University, Nablus 44839, Palestine. ${ }^{3}$ WHO Collaborating Centre for Drug Information, National Poison Centre, University Sains Malaysia (USM), 11800 Gelugor, Penang, Malaysia. ${ }^{4}$ Department of Pharmacology and Toxicology, College of Medicine and Health Sciences, An-Najah National University, Nablus 44839, Palestine. ${ }^{5}$ Department of Anatomy, Biochemistry and Genetics, College of Medicine and Health Sciences, An-Najah National University, Nablus 44839, Palestine.

\section{Acknowledgements}

The authors would like to thank An-Najah National University for providing the opportunity to access the most recent information sources such as the Scopus database.

\section{Competing interests}

The authors declare that they have no competing interests.

Received: 23 August 2015 Accepted: 12 October 2015

Published online: 19 October 2015

\section{References}

Abramo G, D'Angelo CA, Di Costa F (2009) Research collaboration and productivity: is there correlation? High Educ 57(2):155-171

Acevedo AM, Gomez A, Becerra HA, Rios AP, Zambrano PC, Obando EP, MartiCarvajal AJ, Carranza H, Vargas CA, Otero JM, Reveiz L, Cardona AF (2014) Distribution and trends of hematology and oncology research in Latin America: a decade of uncertainty. Cancer 120(8):1237-1245

Ash-Bernal R, Wise R, Wright SM (2004) Acquired methemoglobinemia: a retrospective series of 138 cases at 2 teaching hospitals. Medicine (Baltimore) 83(5):265-273
Barker SJ, Tremper KK, Hyatt J (1989) Effects of methemoglobinemia on pulse oximetry and mixed venous oximetry. Anesthesiology 70(1):112-117

Benamer HT, Bakoush O (2009) Arab nations lagging behind other Middle Eastern countries in biomedical research: a comparative study. BMC Med Res Methodol 9:26

Bird SB (2008) Journal impact factors, $h$ indices, and citation analyses in toxicology. J Med Toxicol 4(4):261-274

Cardona G, Sanz JP (2014) Citation parameters of contact lens-related articles published in the ophthalmic literature. Eye Contact Lens 40(5):301-304

Carey BW, Wilson JL (1940) Methemoglobinemia following sulfanilamide and sulfapyridine therapy in infants and children. J Pediatr 17(1):38-43

Cheng T, Zhang G (2013) Worldwide research productivity in the field of rheumatology from 1996 to 2010: a bibliometric analysis. Rheumatology (Oxford) 52(9):1630-1634

Coleman MD, Coleman NA (1996) Drug-induced methaemoglobinaemia. Treatment issues. Drug Saf 14(6):394-405

Cortazzo JA, Lichtman AD (2014) Methemoglobinemia: a review and recommendations for management. J Cardiothorac Vasc Anesth 28(4):1055-1059

Costas R, Bordons M (2007) The h-index: advantages, limitations and its relation with other bibliometric indicators at the micro level. J Informetr 1(3):193-203

Curry S (1982) Methemoglobinemia. Ann Emerg Med 11(4):214-221

Delirrad M, Rashidi A, Karimi S (2013) A bibliometric analysis of toxicology publications of Iran and Turkey in ISI Web of Science. Iranian J Toxicol 6(19):735-745

Essential Science Indicators (2012) Top 20 Countries in ALL FIELDS, 2001-August 31, 2011. http://www.archive.sciencewatch.com/dr/ cou/2011/11decALL/. Accessed 20 Sept 2013

Falagas ME, Pitsouni El, Malietzis GA, Pappas G (2008) Comparison of PubMed Scopus, web of science, and Google scholar: strengths and weaknesses. FASEB J 22(2):338-342

Fan AM, Steinberg VE (1996) Health implications of nitrate and nitrite in drinking water: an update on methemoglobinemia occurrence and reproductive and developmental toxicity. Regul Toxicol Pharmacol 23(1 Pt 1):35-43

Fewtrell L (2004) Drinking-water nitrate, methemoglobinemia, and global burden of disease: a discussion. Environ Health Perspect 112(14):1371-1374

Foley JA, Della Sala S (2014) Papers from international collaborations have higher impact. Cortex 53:A1-A3

Freeman RB, Huang W (2014) Collaboration: strength in diversity. Nature 513(7518):305

Guay J (2009) Methemoglobinemia related to local anesthetics: a summary of 242 episodes. Anesth Analg 108(3):837-845

Hirsch JE (2005) An index to quantify an individual's scientific research output. Proc Natl Acad Sci USA 102(46):16569-16572

Hsu YH, Ho YS (2014) Highly cited articles in health care sciences and services field in Science Citation Index Expanded. A bibliometric analysis for 1958-2012. Method Inf Med 53(6):446-458

Jang DH, Rusyniak DE (2011) Hard impact: journal impact factor and JMT. J Med Toxicol 7(4):256-258

LiW, Zhao Y (2015) Bibliometric analysis of global environmental assessment research in a 20-year period. Environ Impact Assess Rev 50:158-166

Li BZ, Pan HF, Ye DQ (2013) A bibliometric study of literature on SLE research in PubMed (2002-2011). Lupus 22(8):772-777

Lipsman N, Woodside DB, Lozano AM (2014) Trends in Anorexia Nervosa Research: an analysis of the top 100 most cited works. Eur Eat Disord Rev 22(1):9-14

Lopez-Munoz F, Castle D, Shen W, Moreno R, Huelves L, Perez-Nieto M, Noriega C, Rubio G, Molina J, Alamo C (2013) The Australian contribution to the literature on atypical antipsychotic drugs: a bibliometric study. Australas Psychiatry 21(4):343-345

Man JP, Weinkauf JG, Tsang M, Sin DD (2004) Why do some countries publish more than others? An international comparison of research funding English proficiency and publication output in highly ranked general medical journals. Eur J Epidemiol 19(8):811-817

Mansouri A, Lurie AA (1993) Concise review: methemoglobinemia. Am J Hematol 42(1):7-12 
Miro O, Montori E, Ramos X, Galicia M, Nogue S (2009) Trends in research activity in toxicology and by toxicologists in seven European countries. Toxicol Lett 189(1):1-4

Mitsides N, Green D, Middleton R, New D, Lamerton E, Allen J, Redshaw J, Chadwick PR, Subudhi CPK, Wood G (2014) Dapsone-induced methemoglobinemia in renal transplant recipients: more prevalent than previously thought. Transpl Infect Dis 16(1):37-43

Morimoto T, Rahman M, Fukui T (2003) International comparison of research productivity in hematology. Int J Hematol 77(2):192-195

Nilsson A, Engberg G, Henneberg S, Danielson K, De Verdier CH (1990) Inverse relationship between age-dependent erythrocyte activity of methaemoglobin reductase and prilocaine-induced methaemoglobinaemia during infancy. Br J Anaesth 64(1):72-76

Rahman M, Fukui T (2001) Factors related to biomedical research productivity in Asian countries. J Epidemiol 11(4):199-202

Rahman M, Fukui T (2003) Biomedical research productivity: factors across the countries. Int J Technol Assess Health Care 19(1):249-252

Ramos JM, Gonzalez-Alcaide G, Bolanos-Pizarro M (2013) Bibliometric analysis of leishmaniasis research in Medline (1945-2010). Parasit Vectors 6:55

Rymer BC, Choa RM (2015) A worldwide bibliometric analysis of published literature in plastic and reconstructive surgery. J Plast Reconstr Aesthet Surg 68(9):1304-1308

Scimago (2014) Scimago journal and country rank. http://www.scimagojr. com/SCImagoJournalRank.pdf. Accessed 4 Apr 2014

Sharma B, Lawrence DW (2014) Top-cited articles in traumatic brain injury. Front Hum Neurosci 8:879

Skold A, Cosco DL, Klein R (2011) Methemoglobinemia: pathogenesis, diagnosis, and management. South Med J 104(11):757-761

Smith DR (2009) Highly cited articles in environmental and occupational health, 1919-1960. Arch Environ Occup Health 64(Suppl 1):32-42

Smith DR (2010) Identifying a set of 'core'journals in occupational health, part 2: lists derived by bibliometric techniques. Arch Environ Occup Health 65(3):173-175

Smith D (2012) Impact factors, scientometrics and the history of citationbased research. Scientometrics 92(2):419-427

Sohn CH, Seo DW, Ryoo SM, Lee JH, Kim WY, Lim KS, Oh BJ (2014) Lifethreatening methemoglobinemia after unintentional ingestion of antifreeze admixtures containing sodium nitrite in the construction sites. Clin Toxicol (Phila) 52(1):44-47

Sweileh WM, Zyoud SH, Sawalha AF, Abu-Taha A, Hussein A, Al-Jabi SW (2013) Medical and biomedical research productivity from Palestine, 2002-2011. BMC Res Note 6:41

Sweileh WM, Al-Jabi SW, Sawalha AF, Zyoud SH (2014a) Bibliometric analysis of nutrition and dietetics research activity in Arab countries using ISI Web of Science database. Springerplus 3:718

Sweileh WM, Al-Jabi SW, Zyoud SH, Sawalha AF, Ghanim MA (2014b) Osteoporosis is a neglected health priority in Arab World: a comparative bibliometric analysis. Springerplus 3:427

Sweileh WM, Al-Jabi SW, Abuzanat A, Sawalha AF, AbuTaha AS, Ghanim MA, Zyoud SH (2015a) Assessment of research productivity of Arab countries in the field of infectious diseases using Web of Science database. Infect Dis Poverty 4(1):2

Sweileh WM, Al-Jabi SW, Shanti Yl, Sawalha AF, Zyoud SH (2015b) Contribution of Arab researchers to ophthalmology: a bibliometric and comparative analysis. Springerplus 4:42

Sweileh WM, Zyoud SH, Al-Jabi SW, Sawalha AF (2015c) Contribution of Arab countries to breast cancer research: comparison with non-Arab Middle Eastern countries. BMC Women Health 15:25

Therattil PJ, Hoppe IC, Granick MS, Lee ES (2014) Application of the h-Index in academic plastic surgery. Ann Plast Surg 134(4S-1):165-166

Wallin JA (2005) Bibliometric methods: pitfalls and possibilities. Basic Clin Pharmacol Toxicol 97(5):261-275

Wieringa A, Bethlehem C, Hoogendoorn M, Van Der Maten J, Van Roon EN (2014) Very late recovery of dapsone-induced methemoglobinemia. Clin Toxicol (Phila) 52(1):80-81

World Bank Group (2013) Countries and Economies 2012. http://www.data. worldbank.org/country. Accessed 25 Nov 2013

Wright RO, Lewander WJ, Woolf AD (1999) Methemoglobinemia: etiology, pharmacology, and clinical management. Ann Emerg Med 34(5):646-656

Wykes T, Lipczynska S, Guha M (2013) The h-index, the citation rating, impact factors and the aspiring researcher. J Ment Health 22(6):467-473

Zhang S, Manor B, Li L (2015) H-index is important for postural control for people with impaired foot sole sensation. PLoS One 10(3):e0121847

Zyoud SH, Al-Jabi S, Sweileh W, Awang R (2014a) A bibliometric analysis of research productivity of Malaysian publications in leading toxicology journals during a 10-year period (2003-2012). Hum Exp Toxicol 33(12):1284-1293

Zyoud SH, Al-Jabi SW, Sweileh WM (2014b) Bibliometric analysis of scientific publications on waterpipe (narghile, shisha, hookah) tobacco smoking during the period 2003-2012. Tob Induc Dis 12(1):7

Zyoud SH, Al-Jabi SW, Sweileh WM, Awang R (2014C) A bibliometric analysis of toxicology research productivity in Middle Eastern Arab countries during a 10-year period (2003-2012). Health Res Policy Syst 12(1):4

Zyoud SH, Al-Jabi SW, Sweileh WM, Awang R (2014d) A Scopus-based examination of tobacco use publications in Middle Eastern Arab countries during the period 2003-2012. Harm Reduct J 11:14

Zyoud SH, Al-Jabi SW, Sweileh WM (2015a) Worldwide research productivity of paracetamol (acetaminophen) poisoning: a bibliometric analysis (2003-2012). Hum Exp Toxicol 34(1):12-23

Zyoud SH, Al-Jabi SW, Sweileh WM, Al-Khalil S, Zyoud SH, Sawalha AF, Awang $\mathrm{R}$ (2015b) The Arab world's contribution to solid waste literature: a bibliometric analysis. J Occup Med Toxicol 10:35

Zyoud SH, Al-Jabi SW, Sweileh WM, Awang R, Waring WS (2015c) Bibliometric profile of the global scientific research on methanol poisoning (19022012). J Occup Med Toxicol 10:17

Zyoud SH, Al-Jabi SW, Sweileh WM, Awang R, Waring WS (2015d) Globa research productivity of $\mathrm{N}$-acetylcysteine use in paracetamol overdose: a bibliometric analysis (1976-2012). Hum Exp Toxicol 34(10):1006-1016

\section{Submit your manuscript to a SpringerOpen ${ }^{\circ}$ journal and benefit from:}

Convenient online submission

- Rigorous peer review

- Immediate publication on acceptance

- Open access: articles freely available online

- High visibility within the field

- Retaining the copyright to your article

Submit your next manuscript at $>$ springeropen.com 